Research Paper

\title{
Performance Enhancement of Solar Photovoltaic Panels using Air-water Mixture and Sustainable Solutions to Off-Grid Electrification
}

\author{
Nithin Sha Najeeb ${ }^{1}$, Prashant Kumar Soori ${ }^{2, *}$ and Iyad Al Madanat ${ }^{3}$ \\ 1 School of Engineering \& Physical Sciences, Heriot Watt University Dubai, Academic City, DUBAI \\ (U.A.E), Email: $\underline{\text { nnv2@hw.ac.uk }}$
}

2 Assistant Professor, School of Engineering \& Physical Sciences, Heriot Watt University Dubai, Academic City, DUBAI (U.A.E), Email: p.k.soori@hw.ac.uk, Telephone: +971-555458639

3. General Manager, Phoenix Contact Middle East, Academic City, DUBAI (U.A.E.)

Email: imadanat@phoenixcontact.com

* Prashant Kumar Soori, School of Engineering \& Physical Sciences, Heriot Watt University, Academic City, P.O.Box: 294345, DUBAI (UAE), Tel.: +971-55-5458639

\begin{abstract}
:
Solar Energy has enormous potential to fulfill the energy requirements of the world and can be extracted using solar cells. However, the solar cells are affected by poor efficiency and further affected by wind speed, orientation of the panel, temperature and dust deposition. There are different cleaning technologies devised by many industry experts to clean the solar panels. However, they are facing drawbacks when deployed in the solar farm. An efficient cleaning system, along with an added cooling system must be devised, so that the solar panels must be cleaned and cooled often to maximize the energy production. This paper presents a low-cost, energy-efficient, smart and innovative dust cleaning and cooling system for Photovoltaic (PV) Panels. The system is designed, fabricated, fully-automated using Programmable Logic Controller (PLC) and tested successfully. A battery-charging kiosk, capable of charging two, $24 \mathrm{~V}$ Lead Acid Batteries embedded within this prototype, shall provide clean-energy in a sustainable manner to the rural communities of the developing nations. The user can check the status of the battery such as battery voltage, battery temperature, and state of charge on the Human Machine Interface (HMI) panel while charging the batteries.
\end{abstract}

Keywords: Dust Accumulation; Human Machine Interface (HMI); Programmable Logic Controller (PLC); Soiling 


\section{Page 2}

\section{Introduction}

Solar energy is an abundant energy resource available on the earth. Solar energy can be captured in the form of heat to produce electricity (Concentrated Solar Power Plant) or direct conversion of solar energy to electricity (Photovoltaic Module) is also possible. The solar energy is a renewable resource which almost comes with zero carbon emission. The electricity generation using solar panel is the best and promising alternative. Electricity generation using solar power especially in remote areas is a promising and sustainable solution of providing clean energy [1]. The solar energy can be used to meet the world's energy crisis. Though the solar energy is easily available, however its utilization using solar panel is affected by many factors such as dust accumulation or soling and increase in cell temperature. Dust accumulation or soiling is one of the prime factors which affects the performance of the solar panel in Middle East and African regions [2]. Dust can be classified as particles which are having diameters less than 500 micrometers [3]. The reduction in the performance of the solar panel is not uniform, because the dust accumulation is not uniform, and it is highly dependent on the geographical site conditions [4]. Reports have been published wherein it was showed that, the loss of power production due to the soiling issues occurs mainly in the solar energy systems such as PV or Concentrated Solar Power (CSP) plants [5] [6].

The dust deposited on the solar panels in the solar farms block the radiation from the sun reaching the solar panel. The soiling rate varies from region to region and it also depends on the physical and chemical properties of the dust according to geographical conditions of the region. The researchers have reported that the dust accumulation depends on wind speed, atmospheric dust concentration, location and time chosen/rate of cleaning the solar panels [7]. In general, the more the dust accumulated on the solar panel, greater the reduction in the power output from the solar panel. The power output of the solar PV panel is directly proportional to the intensity of sunlight striking the panel's surface. The harsh climatic conditions along with high temperature as well as humidity also play a vital role in effective utilization of solar energy in these regions.

The concern was raised for solar panels placed in dry semi-arid areas (Gulf regions) because of the three environmental factors which resulted in the reduction in the power output from the solar panel: High Ambient temperature, High humidity and Dust storms [8] [9]. The dust deposition on the solar panel which are particularly installed in dusty areas affects the power production. The location of solar panels in areas which receive more sunlight are usually placed in arid or semi-arid areas and this leads to the loss of $1 \%$ power reduction due to dust accumulation [10]. In dusty desert areas where the solar irradiation is highly available, dust deposition, hindrance of solar irradiation due to passing of clouds causes hindrance in power production [11]. There are other factors which acts a barrier to the performance of the solar panel. The factors are wind speed, energy conversion devices, temperature, humidity, regional characteristics such as plants, traffic and air pollution play an important role in dust deposition [12]. To improve the efficiency of the solar panel, the solar module must be cleaned with a very efficient cleaning technique. Desert storms along with light rains is a common phenomenon in desert environment which will lead to the formation of cemented particles on the top of the solar panel thereby blocking the solar irradiance from reaching the solar cell [13]. In dry months, when there is no rainfall, to remove the cemented particles from the solar panel, the issues worsen, and the performance of the panel reduces. Hence, for the solar panel to produce a stable output, the panel should be kept cleaned to absorb the incoming radiation. 
Page 3

There are many methods available in the market for cleaning the PV panels. Existing methods are Manual Cleaning, use of water sprinklers, use of Robotics for cleaning, Brushing and Wiping, Anti-Soling Coating and Electrodynamic Screens. Manual cleaning comes with the disadvantage that, it is time consuming and is a labour intensive method [14]. The chances of scratches on the panel is very high during the cleaning process. Enough quantity of water must be carried along in a truck for cleaning the solar panel. Robotic cleaning has a drawback in which it takes more time to clean the solar array. The reason being, these devices must move vertically and horizontally for cleaning the panels [13]. These devices operate using battery and needs periodic battery replacement. Sprinkler system has a short coming in which it consumes a lot of water for cleaning the solar panels. The solar panels which is usually in the desert regions has a problem with the availability of water, and hence this is not a viable method. The electrodynamic screen uses high voltage to remove the dust from the solar panel. The high voltage is used in generating the electric field which produces a travelling wave, thereby pushing the dust away from the solar panels [15] [16]. Solar panel cleaning using detergents is time consuming, costly and it can even corrode the frames of the solar panel [17].

This paper explains a cleaning mechanism which uses pressurized air and water to clean the dusty solar panels as well as to cool down the panels in the event of high temperature. The prototype system is designed, fabricated and tested successfully at Heriot Watt University Dubai. The novelty of this paper is that, the pressurized air and water was also tested to check whether, the mixture can also act as a coolant in addition to the process of cleaning the solar panels. The researchers reported that, increase in cell temperature results in lesser power production [18] [19]. The photovoltaic efficiency depends on the current and voltage of the solar panel which depends on the temperature. This leads to the linear reduction in performance as temperature increases [20]. The solar module when absorbs the radiation, the temperature increases which will result in decrease in efficiency. The researchers concluded that cell efficiency decreases by $0.45 \%$ for every degree rise in temperature [21]. The reduction of cell temperature is therefore necessary in enhancing the power output of the solar panel. The cooling of solar panel is only way to reduce the temperature rise of the solar panels. Additionally, the increase in temperature is also a threat to the panels as it leads to high densities of current and heat fluxes. Proper cooling technique is therefore a necessity in preventing the performance degradation of PV panels which shall bring irreversible damage. The cooling of PV panels is very important and an efficient technique to cool down the solar panels without using additional energy, shall help in increased power production.

The proposed method of cleaning and cooling the PV panel presented in this research work has no guard rails, less operator intervention, no need of any self-cleaning, no moving parts on the panel surface and it can also withstand harsh climatic conditions (especially in the Middle-East). The system is designed, fabricated, fully automated using PLC (ILC 171 ETH, Phoenix Contact) and tested successfully at Heriot Watt University Dubai. The system is expected to act as a dual-purpose technology: cleaning and cooling jobs.

\section{Proposed Methodology}

In the proposed method, the mixture of pressurized air and water in a designed pressure (the designed pressure is maintained to 2.5 bar for air and 4 bar for water) is used to clean and cool the 
Page 4

dusty PV panels along with the application of anti-soiling coating. In the initial phase of this research work, the solar panels are coated with a thin layer of anti-soiling coating before spraying the air-water mixture. This coating is applied on the panel to prevent the dirt from sticking to the solar panel. The panel is cleaned using isopropyl alcohol, followed by coating applied in circular motions on the panel. The panel is left undisturbed for allowing the bonding of the coating to form on the solar panel. Later, using a soft cotton cloth, the panel is wiped out until no visible films are seen on the panel. The solar panel is installed in the farm. During the process of cleaning and cooling the dusty panels, the air and water are fed into a common point where it can mix in a designed pressure before spraying on the dusty solar panel. The mixture is sprayed through a specially designed Nozzle resulting in Flat -fan spray which helps in more area coverage with less amount of water. The pressure for air and water is regulated using air and water pressure regulators. The flow rate of spraying the mixture can be adjusted using the nozzle. Depending on the flow rate adjustment, the spray mixture can be controlled and thereby cleaning the dusty solar panel. To the inlet of the Nozzle, $6 \mathrm{~mm}$ diameter hose is connected for both air and water outlets, and an area of $0.7 \mathrm{~m}^{2}$ is covered using less amount of water. The pictorial representation of the fabricated prototype is depicted in the Figure 1.

Figure 1: Pictorial representation of the fabricated prototype

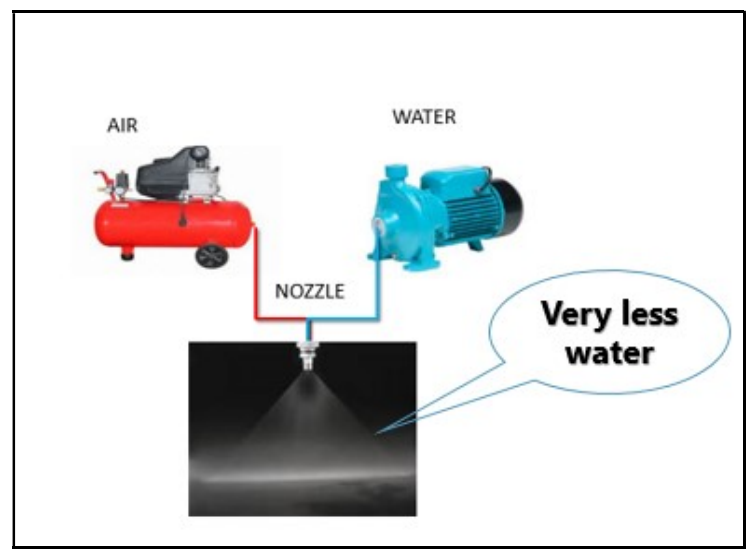

The system is integrated with automation procedures using PLC (ILC $171 \mathrm{ETH}$, Phoenix Contact) to perform the cleaning process. The duration of the whole process is programmed to be 240 seconds in which 60 seconds is where the actual cleaning process takes place. The cleaning time can be adjusted according to the site conditions. The entire process is programmed into PLC using Ladder Logic. A user-friendly design approach has been incorporated using HMI panel as an interface to control and monitor the progress of the entire cleaning operation.

The air compressor and water pump are connected through a pressure regulator to regulate the pressure and then fed into the Pneumatic Nozzle which is placed on the top of dusty solar panel. The solenoid valve is used for automation purpose where they remain closed at the time when the air line and water line is getting pressurized. The solenoid valves are used instead of the already built in manual valves. The control logic of the solar panel cleaning and the components used in the prototype working model is highlighted in Figure 2. 
Figure 2: Control logic of Solar Panel Cleaning System

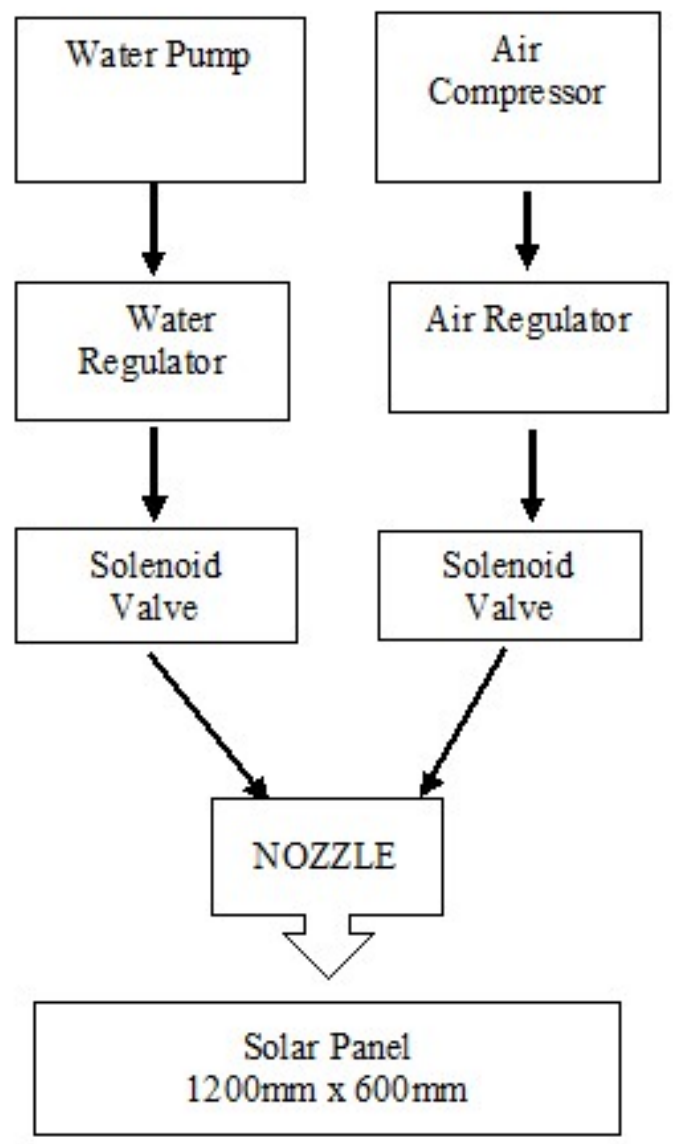

\subsection{Automation of Solar Panel Cleaning and Cooling System}

The prototype of solar panel cleaning and cooling system is built and automated using ILC $131 \mathrm{ETH}$ PLC and the user interface is incorporated using an HMI panel. The automation logic is based on the timer-based signals from the PLC. The whole process runs on the timer basis, and the signal from the PLC to the field components is activated based on the time programmed into the PLC. In total, it has three commands: first one for the air compressor, second one for water pump and third one for solenoid valves of both air and water lines. These commands are given by the PLC during the entire cleaning process.

When the command is given by the user from the HMI Panel, the PLC gives a signal to the air compressor, and the air compressor switches on. The compressor tanks build pressure of the air up to 2.5 bar, and the compressor switches off due to the internal circuitry. The time taken by the air compressor to build pressure of the air up to 2.5 bar is designed for 120 seconds. Figure 3 shows the status of air compressor which can be seen on the HMI panel display.

Figure 3: Air compressor active status displayed on the HMI Panel 


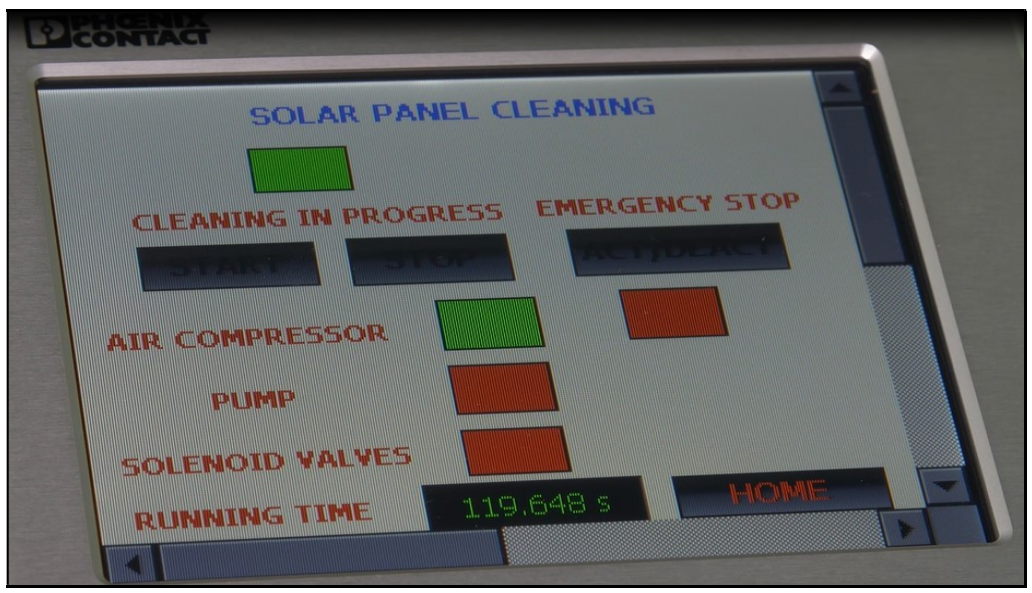

Page 6

When the air compressor has built the pressure, the PLC is programmed to send a signal to turn on the water pump. The water pump will turn on, and the water line will be pressurized. The time taken for water line to get pressurized is programmed for 60 seconds. The screenshot showing the status of the water pump displayed on the HMI panel is shown in Figure 4.

Figure 4: Water Pump status displayed on the HMI Panel

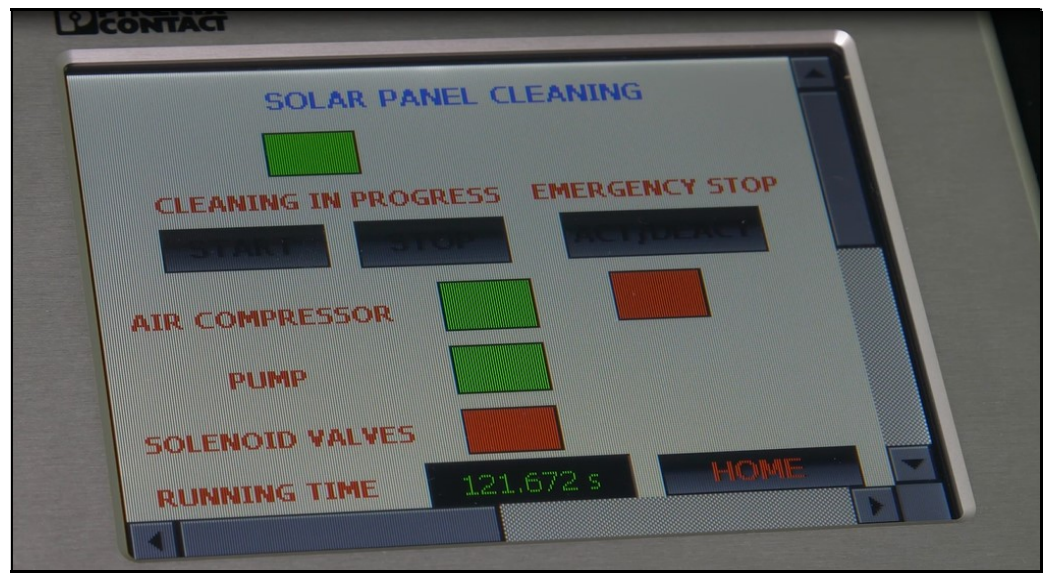

After 180 seconds, the signals are given to the solenoid valves simultaneously, to remain open for 60 seconds. The entire duration for cleaning process is 240 seconds (or 4 Minutes). The status of solenoid valves displayed on the HMI panel is depicted in Figure 5. The time duration of cleaning process can be adjusted according to the site conditions. This is possible by changing the ladder logic program of the PLC.

Figure 5: Solenoid Valve active status on the HMI panel 


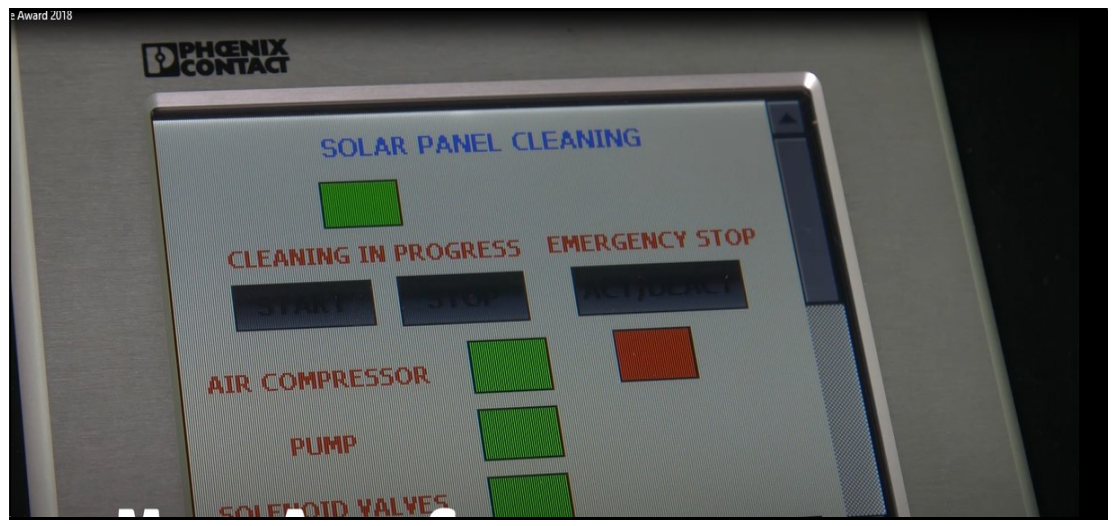

Page 7

The ladder logic sequence for cooling process is same as that of the cleaning process of the solar panel. The cooling process can be performed everyone hour starting 12 noon ending at 5 PM in a day to maximize the power production. The PLC Ladder logic program was developed using PC Worx (Phoenix Contact) software. The developed control logic is given in Figure 6.

Figure 6: Developed Ladder logic control schematics for Solar panel cleaning/cooling system

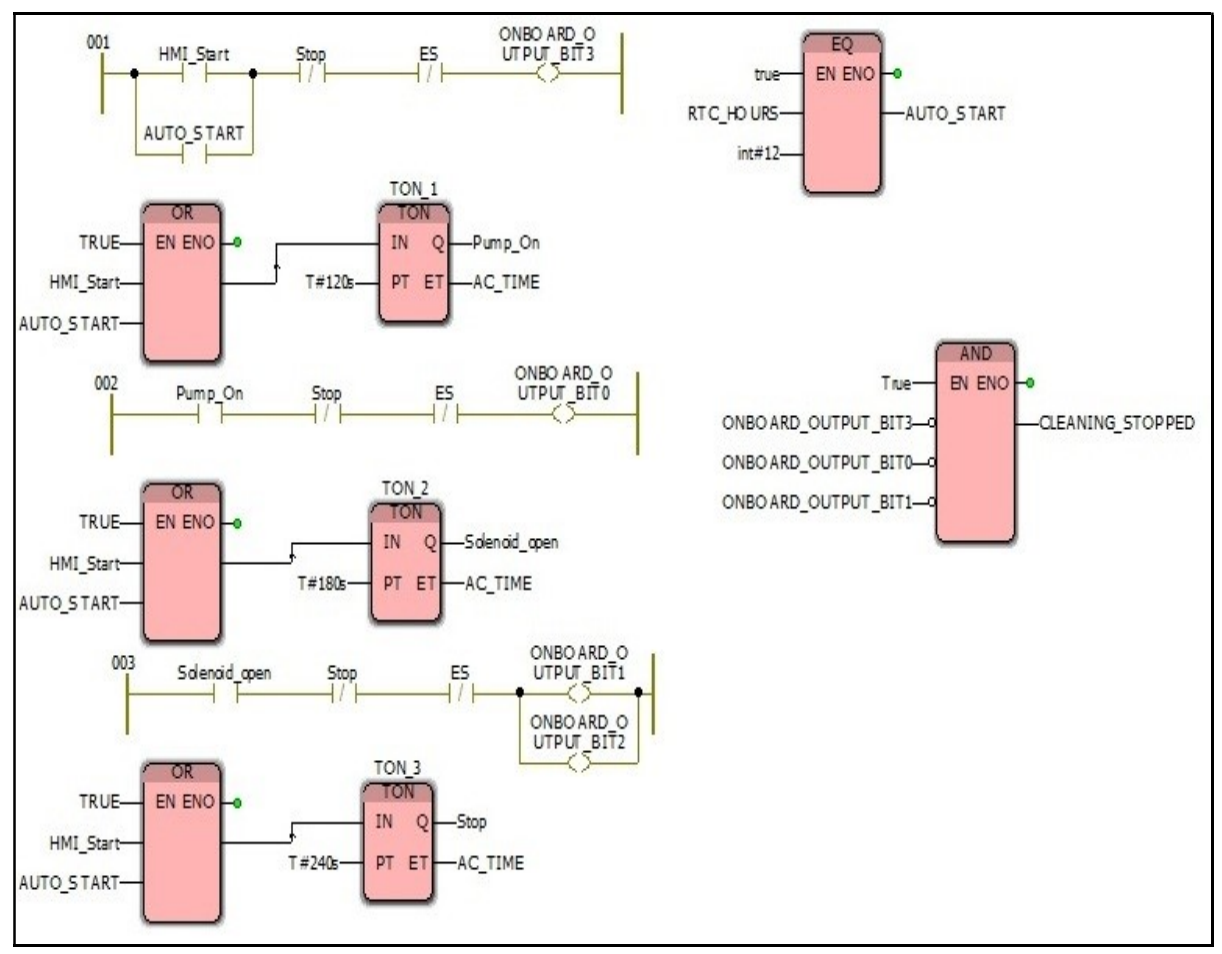

The ILC 171 ETH PLC also comes with a Real-Time clock Facility feature. The use of real-time clock facility feature is that, the PLC on its own can initiate process without the user giving the command through HMI panel. Figure 7 shows the functional block schematics implemented in the ladder logic program for the activation of real time clock feature of ILC 131 ETH PLC module. The advantage of this feature is that, without an operator giving a command, the process of cleaning and cooling can take place at the programmed time to the PLC. Hence operator doesn't need to be in the control room. In this research work, the real time clock is programmed to be 120 'clock noon time. 
Figure 7: Functional block of the programmed real time clock feature

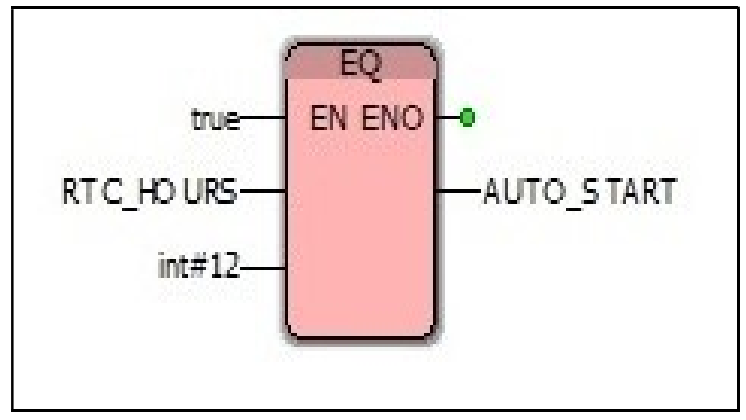

\section{Results and Discussion}

Two identical test benches were set up in Heriot-Watt University Dubai Campus, one with cleaned panel and another with un-cleaned solar panel. Identical Panels and loads were chosen for collecting the data. The chosen panel was a polycrystalline $60 \mathrm{~W}$ Solar Panel. The specification of the panel is depicted in the Table 1.

Table 1: Specification of the Solar Panel

\begin{tabular}{|l|l|}
\hline Solar Panel & Specification \\
\hline Maximum Power $\left(\mathrm{P}_{\mathrm{max}}\right)$ & $60 \pm 3 \% \mathrm{~W}$ \\
\hline Maximum Power Current $\left(\mathrm{I}_{\mathrm{mp}}\right)$ & $3.3 \mathrm{~A}$ \\
\hline Maximum Power Voltage $\left(\mathrm{V}_{\mathrm{mp}}\right)$ & $18 \mathrm{~V}$ \\
\hline Short circuit Current $\left(\mathrm{I}_{\mathrm{sc}}\right)$ & $3.68 \mathrm{~A}$ \\
\hline Open circuit Voltage $\left(\mathrm{V}_{\mathrm{oc}}\right)$ & $21.2 \mathrm{~V}$ \\
\hline Maximum System Voltage & $\mathrm{DC} 1000 \mathrm{~V}$ \\
\hline Maximum Series Voltage & $10 \mathrm{~A}$ \\
\hline Nominal Operating Temperature $(\mathrm{NOCT})$ & $-45^{\circ} \mathrm{C}$ to $80^{\circ} \mathrm{C}$ \\
\hline
\end{tabular}

According to the site conditions (Heriot -Watt University Dubai Campus), the panel is kept at $50^{\circ}$ facing south-east. The Voltage (V) and current (A) readings were taken at every half an hour interval for cleaned and un-cleaned panel of the same ratings. The test benches were tested with identical load. Figure 8 depicts the connection diagram of the test rig up. This experiment was conducted on January 22, 2018. The results of the tests are given in Table 2 and 3.

Figure 8: Test set-up of two identical Test benches

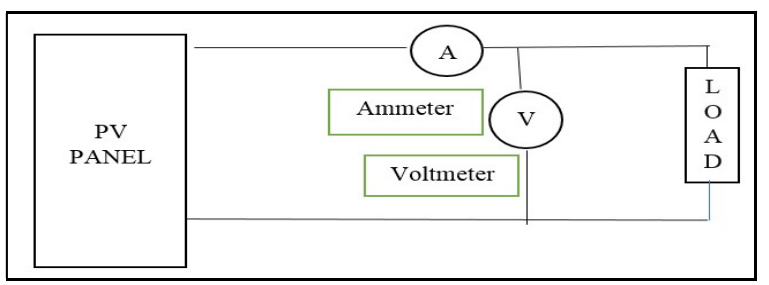


Table 2: Results with cleaned panel

\begin{tabular}{|l|l|l|l|l|}
\hline S. No & Time & Voltage (V) & Current (A) & Power (W) \\
\hline 1 & $11: 00 \mathrm{am}$ & 12.71 & 2.08 & 26.43 \\
\hline 2 & $11: 30 \mathrm{am}$ & 15.17 & 2.31 & 35.04 \\
\hline 3 & $12: 00 \mathrm{pm}$ & 17.41 & 2.41 & 41.95 \\
\hline 4 & $12: 30 \mathrm{pm}$ & 15.50 & 2.75 & 35.65 \\
\hline 5 & $1: 00 \mathrm{pm}$ & 12.00 & 2.10 & 25.20 \\
\hline
\end{tabular}

Table 3: Results with Uncleaned panel

\begin{tabular}{|l|l|l|l|l|}
\hline S. No & Time & Voltage $(\mathrm{V})$ & Current $(\mathrm{A})$ & Power $(\mathrm{W})$ \\
\hline 1 & $11: 00 \mathrm{am}$ & 8.20 & 2.60 & 21.32 \\
\hline 2 & $11: 30 \mathrm{pm}$ & 12.10 & 2.00 & 24.20 \\
\hline 3 & $12: 00 \mathrm{pm}$ & 15.78 & 2.0 & 31.56 \\
\hline 4 & $12: 30 \mathrm{pm}$ & 13.0 & 2.1 & 27.31 \\
\hline 5 & $1: 00 \mathrm{pm}$ & 9.30 & 1.8 & 16.74 \\
\hline
\end{tabular}

It is evident from the results presented in Tables 2 and 3 that, there is a significant power loss when the solar panel is left un-cleaned. This justifies the need for cleaning the panels periodically to capture the clean energy. The readings from the same identical panels showed that, with the same site conditions the power produced is significantly more with the cleaned panel than that obtained with the un-cleaned panel. At 12 noon, which is the peak time for power production, the power output of the cleaned panel is observed to be $32 \%$ more than the un-cleaned panel.

To investigate the importance of cooling the panels, again the same two identical test benches were used. However, fabricated system using air-water mixture was deployed to clean and cool the panels. The results are tabulated in Table 4 and 5.

Table 4: Results without cooling

\begin{tabular}{|l|l|l|l|l|l|}
\hline S. No & Time & Voltage $(\mathrm{V})$ & Current $(\mathrm{A})$ & Power $(\mathrm{W})$ & Temperature $\left({ }^{\circ} \mathrm{C}\right)$ \\
\hline 1 & $2: 00 \mathrm{pm}$ & 7.1 & 1.4 & 9.9 & 31.9 \\
\hline 2 & $2: 15 \mathrm{pm}$ & 8.0 & 1.5 & 12.0 & 45.0 \\
\hline 3 & $2: 30 \mathrm{pm}$ & 7.5 & 1.4 & 11.2 & 47.0 \\
\hline 4 & $2: 45 \mathrm{pm}$ & 7.0 & 1.4 & 9.8 & 45.8 \\
\hline 5 & $3: 00 \mathrm{pm}$ & 6.4 & 1.4 & 8.9 & 47.1 \\
\hline
\end{tabular}

Table 5: Results after cooling using the fabricated prototype (Spraying Air-Water Mixture using the prototype) 
Page 10

\begin{tabular}{|l|l|l|l|l|l|}
\hline S. No & Time & Voltage $(\mathrm{V})$ & Current $(\mathrm{A})$ & Power $(\mathrm{W})$ & Temperature $\left({ }^{\circ} \mathrm{C}\right)$ \\
\hline 1 & $2: 00 \mathrm{pm}$ & 7.9 & 1.5 & 12 & 31.9 \\
\hline 2 & $2: 15 \mathrm{pm}$ & 8.4 & 1.6 & 13.4 & 29.0 \\
\hline 3 & $2: 30 \mathrm{pm}$ & 8.3 & 1.6 & 13.2 & 30.0 \\
\hline 4 & $2: 45 \mathrm{pm}$ & 7.6 & 1.5 & 11.4 & 33.1 \\
\hline 5 & $3: 00 \mathrm{pm}$ & 6.8 & 1.4 & 9.6 & 32.2 \\
\hline
\end{tabular}

It can be clearly observed from Table 4 and 5 that, the solar panels when placed outside during the peak hours, the power production from the solar panel reduces due to rise in temperature. This is also one of the contributing factors in the reduction of power production in addition to soiling and other related issues. The Air-Water mixture when sprayed on the panel using the prototype, resulted in increased power output from the panel as well as reduction in temperature. Hence it is evident from the results that, the air-water mixture is also acting as a coolant for the solar panels. The cooling timings can be set using PLC timer.

The energy consumption of the various auxiliaries used in the fabricated prototype is presented in Table 6. The total energy consumed for the entire cleaning and cooling process per cycle is observed to be $0.0197 \mathrm{kWh}$. The energy consumption may vary according to the different components and according to the usage depending upon the site conditions in the solar farm. The fabricated prototype is shown in Figure 9.

Table 6: Energy consumption of the components used

\begin{tabular}{|l|l|l|l|}
\hline Equipment & $\begin{array}{l}\text { Power Rating } \\
(\mathrm{W})\end{array}$ & $\begin{array}{l}\text { Operating } \\
\text { Time } \\
\text { (Minutes) }\end{array}$ & $\begin{array}{l}\text { Energy } \\
\text { consumed } \\
(\mathrm{kWh})\end{array}$ \\
\hline Air Compressor & 550 & 2 & 0.018 \\
\hline Water Pump & 80 & 1 & 0.0013 \\
\hline Solenoid Valve & 12 & 1 & 0.0002 \\
\hline Solenoid Valve & 12 & 1 & 0.0002 \\
\hline $\begin{array}{l}\text { Total } \\
\text { Consumption }\end{array}$ & & & $\mathbf{0 . 0 1 9 7}$ \\
\hline
\end{tabular}

Figure 9: Fabricated Prototype 


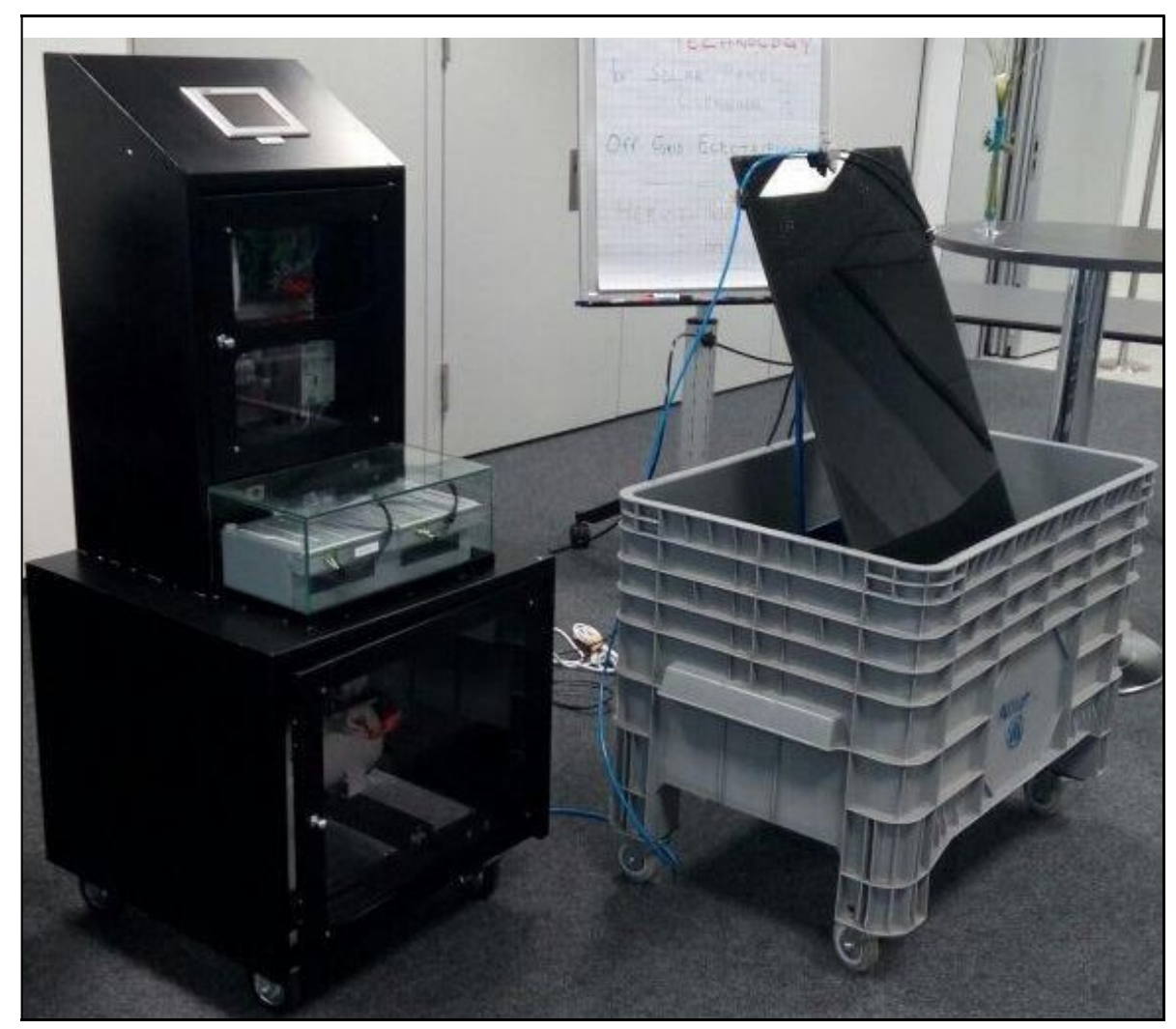

Page 11

The prototype is also designed to charge two $24 \mathrm{~V}$, Lead acid batteries in addition to its cooling and cleaning job. The user-friendly design approach is used in designing battery charging kiosk. Using our battery-charging kiosk, the user can check the status of the battery (battery voltage, battery temperature, state of charge) on HMI panel while charging the batteries. In the fabricated prototype, the batteries are monitored using PLC via an intelligent Uninterruptible Power Supply (UPS) module. The UPS module can measure these three statuses of the battery placed for charging in the kiosk. The same is depicted in Figure 10.

Figure 10: Battery charging status displayed on the HMI Panel 


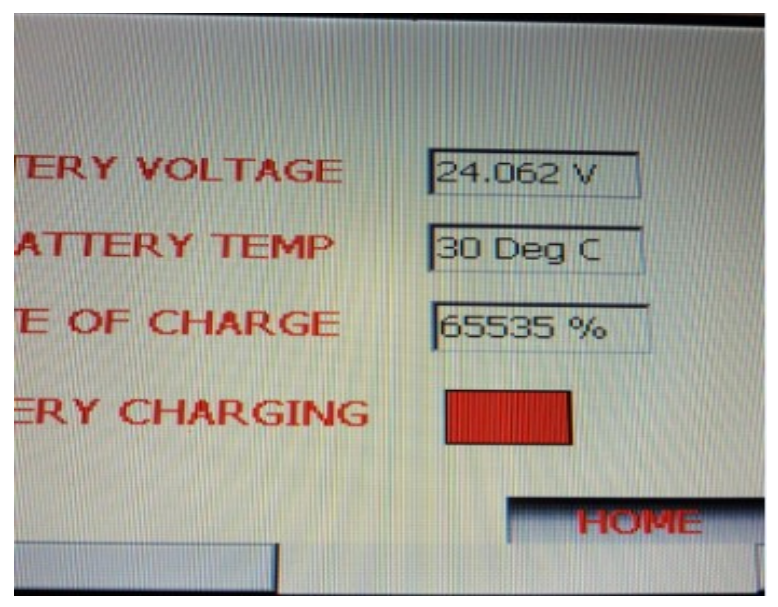

Page 12

\section{Conclusions}

The new innovative idea of solar panel cleaning and cooling system presented in this paper, is a promising technology which can wash away all the industry facing issues. The energy consumption for this new technology is relatively less than the existing technology because there are no moving parts associated with the solar panel cleaning compared to the present day installed technologies. The fabricated prototype has cleaned majority of the panel's surface. The cleanliness depends on the position of the nozzle on the panel to be cleaned and as well as the orientation of the panel. However, the air-water mixture acting as a coolant was proven to be successful.

The cleaning and cooling method presented in this paper has numerous advantages: The operator intervention is less, there are no guard rails, no need of any periodic battery replacement, requires no self-cleaning, requires very less maintenance and it can withstand harsh climatic condition like Middle East and African regions. The proposed methodology shall act as dual-purpose technology, where in it is used to clean the solar panels, and at the same time it can be used as a coolant for the solar panels which are situated in the hot, dry environments.

In the fabricated prototype, two lead acid batteries have also been configured for charging. This charging opens an eye for building charging station in the rural areas of the developing nations. In developing nations, community people still use traditional ways of lighting which brings lot of healthrelated problems to the people. By incorporating such charging stations, people can use Light Emitting Diode (LED) lamps for lighting purposes thereby putting an end to the traditional methods of lighting in rural areas. The carbon emission from the rural places can be easily reduced and introduction of such kiosk will wave good bye to all the health-related issues, fire hazards and it will improve the quality of life of the people.

\section{Acknowledgements}

The authors would like to express sincere thanks to Expo-Live University Innovation Programme, Expo2020 Dubai Initiative for providing the funding for the development of this project. Special thanks to Ms. Fatma Ibrahim, Assistant Manager EXPO Live and her colleagues for their help and Support. 


\section{Page 13}

\section{References}

[1] A. M. Manokar, D. P. Winston, J. D. Mondol, R. Sathyamurthy, A. Kabeel and H. Panchal, "Comparative study of an inclined solar panel basin solar still in passive and active mode," Solar Energy, vol. 169, pp. 206-216, 2018.

[2] E. Y.-T. Chen, L. Ma, B. Guo and H. Liang, "Measurement of dust sweeping force for cleaning solar panels," Solar Energy Materials and Solar Cells, vol. 179, pp. 247-253, 2018.

[3] M. Mani and R. Pillai, "Impact of dust on solar photovoltaic (PV) performance: Research status," Renewable and Sustainable Energy Reviews, vol. 14, no. 9, pp. 3124-3131, 2010.

[4] M.Walwil, S. A.M.Said and Husam, "Fundamental studies on dust fouling effects on PV module performance," Solar Energy, vol. 107, pp. 328-337, 2014.

[5] a. Suellen and C. Costa, "Dust and soiling issues and impacts relating to solar energy systems:" Renewable and Sustainable Energy Reviews, vol. 63, pp. 33-61, 2016.

[6] "A comprehensive review of the impact of dust on the use of solar energy: History, Investigations, results, literature and mitigation approaches," Renewable and Sustainable Energy Reviews, vol. 22, pp. 698-733, 2013.

[7] A. Sayyah, M. N. Horenstein and M. K. Mazumder, "Energy yield loss caused by dust deposition on photovoltaic panels," Solar Energy, vol. 107, pp. 576-604, 2014.

[8] S. A. Said and H. M. Walwil, "Fundamental studies on dust fouling effects on PV module performance," Solar Energy, pp. 328-337, 2014.

[9] N.W.Alnaser, M. Othman, A.A.Dakhel, I.Bataresh, J.k.Lee, S.Najimali, A.Alothman, H.Alshowaikh and W.E.ALnaseer, "Comparison between performance of man-made and naturally cleaned PV panels in a middle of a desert," Renewable and Sustainable Energy Reviews, vol. 82, no. 1, pp. 1048-1055, 2018.

[10] J. K.W.Chesnutt, HusainAshkanani, BingGuo and Chang-YuWu, "Simulation of microscale particle interactions for optimization of an electrodynamic dust shield to clean desert dust from solar panel," Solar Energy, vol. 155, pp. 1197-1207, 2017. 


\section{Page 14}

[11] M.K.Mazumder, R. Sharma, A. Biris, M.N.Horeinstein, J.Zhang, H.Ishihara, J.W.Satrk, S.Blumethal and O.Sadder, "Electrostatic Removal of Particles and its Applications to Self-Cleaning Solar Panels and Solar Concentrators," Developments in Surface Contamination and Cleaning, pp. 149-199, 2011.

[12] IoannisArabatzis, N. Todorova, I. Fasaki, C. Tsesmeli, A. Peppas, W. X. Li and Z. Zhao, "Photocatalytic, self-cleaning, antireflective coating for photovoltaic panels: Characterization and monitoring in real conditions," Solar Energy, vol. 159, no. 1, pp. 251-259, 2018.

[13] D. D. a. N. L.Brahmbhat, "Review of yield increase of solar panels through soiling prevention, and a proposed water-free automated cleaning solution," Renewable and Sustainable Energy Reviews, vol. 82, no. 3, pp. 3306-3313, 2018.

[14] Z. L. C. Zhou, "'Review of Self-Cleaning Method for Solar Cell Array," in Procedia Engineering, 2011.

[15] T. S. H. Kawamoto, "Electrostatic cleaning system for removal of sand from solar panels," 2013.

[16] P. Vasiljev, S. Borodinas, R. Bareikis and A. Struckas, "Ultrasonic system for solar panel cleaning," Sensors and Actuators A: Physical, Vols. 74-78, p. 200, 2013.

[17] A.Syafiq, A.K.Pandey, N.N.Adzman and N. AbdRahim, "Advances in approaches and methods for self-cleaning of solar photovoltaic panels," Solar Energy, vol. 162, pp. 597-619, 2018.

[18] u. A. Hanai, R. B. Hashim, L. E. Chaar and L. A. Lamont, "Environmental effects on a grid connected $900 \mathrm{~W}$ photovoltaic thin-film," Environmental effects on a grid connected $900 \mathrm{~W}$ photovoltaic thin-film, pp. 2615-2622, 2011.

[19] M. AlamImteaz and AmimulAhsan, "Solar panels: Real efficiencies, potential productions and payback periods for major Australian cities," Sustainable Energy Technologies and Environments, vol. 25, pp. 119-125, 2018.

[20] S. E and P. JA, "On the temperature dependent of photovoltaic module electrical performance: a review of effective/power correlations," Solar Energy, vol. 83, pp. 613-624, 2009. 
Page 15

[21] S.-Y. Wu, C. Chen and L. Xiao, "A review of solar photovoltaic panel cooling systems with special reference to Ground coupled central panel cooling system (GC-CPCS)," Renewable Energy, vol. 125, pp. 936-946, 2018. 